\title{
Perilaku Anak Jalanan dan Strategi Pengentasannya di Bandung, Bogor, dan Jakarta
}

\author{
Street Children Behavior and Strategies For \\ Improvement of Street Children Living Condition \\ in Bandung, Bogor, and Jakarta
}

\author{
Sri Tjahjorini ${ }^{*}$, Sumardjo, Margono Slamet ${ }^{2}$, Djoko Susanto ${ }^{3}$, dan Darwis S. Gani ${ }^{2}$ \\ ${ }^{1}$ Pusdiklat Departemen Sosial RI, Jakarta \\ ${ }^{2}$ Dosen Dept. Sains Komunikasi dan Pengembangan Masyarakat FEMA IPB \\ ${ }^{3}$ Pusat Penelitian Gizi Departemen Kesehatan
}

\begin{abstract}
Street child problems, like iceberge phenomenon, of which the regional pockets, the distribution and the age tremendously increase day by day. Since 1997 the government of Indonesia through the Social Ministry has been carrying out efforts to overcome the problems, but up to now the efforts have not yielded the expected results because of the limited information of the problems. The present research was addressed to provide informations on the phenomenon profiles of street children and strategies for their elimination in Bandung, Bogor and Jakarta. Data were collected using structured interviews, focus group discussion and direct observation. The collected data were analysed using parametric and non-parametric statistics. Population were street children, 5-21 years of age. Sample in each region was consisted of 75 persons, 50 males and 25 famales, drawn using cluster random sampling technique, and 25 parents of the respondens as a cross check. The influence of family background on the street children behavior, direct or indirectly, was more obvious compared to that of environmental background. The latter was indirect through sociologic characteristics of the street children particularly on the non formal education. Strategy for elimination of the street children could be equally applied for the whole regions, except for its approach, which can use the TRIBINA, which means Human Building, Environmental Building and Efforts Building could be employed.
\end{abstract}

Key words: street children, family, environment, physical, psychological, sociological characteristics, behaviour

\section{PENDAHULUAN}

UNICEF mengaitkan anak jalanan adalah anak yang menghabiskan sebagian besar waktunya di jalanan untuk bekerja atau beraktifitas lain. Mereka tinggal di jalanan karena tercampakkan atau dicampakkan oleh keluarga-keluarga yang tidak mampu menang-gung beban hidup, terdesak oleh kemiskinan dan kehancuran keluarga. Ketidakmampuan dan kondisi keluarga juga lingkungan secara timbal balik jadi pemicu anak turun ke jalanan, dan berkembang jadi masalah sosial. Popenoe (1989) dalam hal ini menyatakan bahwa

\footnotetext{
* Korespondensi Penulis. Telepon: 081514097775 E-mail: s_tjahjorini@yahoo.com
}

kepadatan penduduk yang tinggi diasosiasikan dengan kematian dan kelahiran yang tinggi, tekanan-tekanan di dalam rumah, kurang efektifnya perhatian terhadap anak dan timbulnya kenakalan anak-anak, juga munculnya masalah lain yang menyertai. Lebih lanjut Popenoe menjelaskan bahwa kepenuhsesakan di rumah, dapat menimbul-kan efek yang mengganggu atau merusak fisik dan psikologi masyarakat, dan secara umum dapat menimbulkan perasaan "kegagalan". Penjelasan di atas memperlihatkan betapa besar pengaruh keluarga dan lingkungan, baik secara fisik maupun non-fisik dalam menghasilkan perilaku yang normatif dan anormatif atau menyimpang (deviant behavior) dalam masyarakat. Studi Popenoe ini memperlihatkan bahwa permasalahan 
sosial yang mengarah pada patologi sosial, salah satunya dimunculkan oleh ketidakberfungsian dan ketidaknyamanan lingkungan dan keluarga bagi individu yang ada di dalamnya.

Faktor lingkungan seperti terjadinya bencana alam kekeringan serta krisis ekonomi yang berkepanjangan pada akhir tahun 1997 semakin mencuatkan permasalahan anak jalanan ke permukaan. Hasil penelitian menunjukkan permasalahan anak jalanan diakibatkan oleh adanya; ketidakserasian keluarga (33\%), kekerasan dalam keluarga $(23 \%)$ dan kemiskinan atau ketidak-mampuan keluarga (98\%), yang seringkali juga bersifat ganda (Suradjat, 1996; Tjahjorini, 2001). Hal ini sejalan dengan hasil penelitian Sulistiati (2001) yang mengemuka-kan alasan anak berada di jalan antara lain karena: kemiskinan (membantu orang tua), broken home, tidak betah di rumah atau di sekolah dan ingin bebas di jalan serta budaya malas. Ketiga hasil penelitian ini memper-lihatkan bahwa penyebab utama dari turunnya anak ke jalan adalah kemiskinan atau ketidak-mampuan keluarga. Akibat lebih lanjut dari kondisi ini, orang tua melibatkan anak dalam upayanya mencukupi kebutuhan keluarga.

Bila dikaji lebih jauh upaya penghapusan kemiskinan sesungguhnya sudah merupakan komitmen dunia yang tertuang dalam Konferensi Tingkat Tinggi Pembangunan Sosial di Kopenhagen 1995 yang menegaskan bahwa pembangunan Bidang Sosial dilaksanakan sejalan dengan pembangunan bidang lainnya. Hal ini sejalan dengan Komitmen dunia lainnya tertuang dalam Millenium Development Goal yang ditandatangani oleh 189 negara di Geneva tahun 2000 dan diperkirakan akan tercapai pada tahun 2015 yang disepakati untuk dilaksanakan oleh negara yang turut serta menandatangani termasuk Indonesia, dengan prioritas utama kesepakatan adalah Pengha-pusan Kemiskinan. Berdasarkan kenyataan di lapangan serta komitmen global di atas, upaya penghapusan kemiskinan menjadi prioritas utama yang vatal dan vital untuk sesegera mungkin dilaksanakan. Hal ini terkait dengan kondisi empirik bahwa permasalahan sosial yang muncul seringkali bersumber pada masalah kemiskinan atau ketidakmampuan keluarga, walaupun untuk kasus masalah anak jalanan kemiskinan tidak menjadi penyebab tunggal.

Masalah sosial anak jalanan terkait pula dengan ketidakmampuan anak memper-oleh haknya. Dalam UndangUndang Nomor 23 Tahun 2002 Tentang Perlindungan Anak, Pasal 23 (1) yang mengamanatkan bahwa negara dan pemerintah menjamin perlin-dungan, pemeliharaan dan kesejahteraan anak dengan memperhatikan hak dan kewajiban orangtua, wali, atau orang lain yang secara hukum bertanggungjawab terhadap anak, khususnya Departemen Sosial untuk melaku-kan perlindungan anak melalui penanganan kasus anak yang memerlukan perlindungan khusus. Berdasarkan hal tersebut jelas bahwa perlindungan, pemeliharaan dan kesejahteraan anak menjadi salah satu kewajiban negara dan pemerintah untuk mewujudkannya.

Berdasarkan hasil survey dan pemetaan sosial anak jalanan yang dilakukan oleh Unika Atmajaya Jakarta dan Departemen Sosial dengan dukungan Asia Development Bank (1999), jumlah anak jalanan adalah 39.861 orang, yang tersebar di 12 kota besar. Pada tahun 2004, menurut Pusat Data dan Informasi Kesejahteraan Sosial Departemen Sosial, jumlah anak jalanan sebesar 98.113 orang, yang tersebar di 30 provinsi. Khusus di Bandung kurang lebih berjumlah 11.000 anak jalanan (Data Dinas Sosial Provinsi Jawa Barat, 2005); di Bogor 514 orang (Data Dinas Sosial Pemda Bogor, 2005); dan di Daerah Khusus Ibukota Jakarta kurang lebih berjumlah 13.000 orang (Data Dinas Sosial DKI Jakarta, 2006).

Sangat boleh jadi keadaan nyata di lapangan jumlah anak jalanan jauh lebih besar dari jumlah di atas. Hal tersebut menunjukkan bahwa permasalahan anak jalanan merupakan fenomena gunung es, 
yang dari tahun ke tahun terjadi peningkatan baik dalam jumlah maupun wilayah penyebarannya. Bila kondisi ini tidak segera ditangani secara tuntas dengan pendekatan yang tepat, dapat berakibat pada terjadinya lost of generations. Di sisi lain masalah anak jalanan, merupakan patologi sosial yang mempengaruhi behavior anak, dengan pola dan sub kultur yang berkembang di jalanan sebagai daya tarik bagi anak yang masih tinggal di rumah tetapi rentan menjadi anak jalanan, untuk turun ke jalanan. Kecenderungannya bila tidak ada upaya mengatasi bukan hanya sekedar turun, tetapi lambat laun bekerja dan hidup di jalan menyatu dengan anak jalanan lain.

Terkait dengan kondisi di atas, masalah anak jalanan jelas merupakan permasalahan yang harus ditangani sampai ke akar-akarnya. Namun karena keterbatasan pemerintah dan luasnya permasalahan, upaya memahami dan mengatasinya perlu melibatkan seluruh komponen masyarakat sebagai bagian dari sistem sosial. Masyarakat dalam hal ini dipandang sebagai suatu sistem yang secara fungsional terintegrasi dalam suatu bentuk equilibrium. Upaya masyarakat mencapai equilibrium hanya mungkin terjadi apabila ada konsensus di antara para anggota masyarakat untuk bersama-sama mengupaya-kannya.

Hal di atas terkait dengan pernyataan Irwanto (1999) bahwa "pemahaman terhadap situasi anak jalanan saja tidak akan memberikan jalan keluar yang efektif untuk mengatasi permasalahan anak jalanan. Agar sebuah intervensi efektif, maka diperlukan pemahaman yang menyeluruh mengenai masyarakat dan keluarga-keluarga anak jalanan. Pemahaman makro (struktural) dan mikro (dinamika keluarga) sangat dibutuh-kan".

Demikian pula upaya penanggulangan masalah sosial anak jalanan, seyogyanya dilakukan dengan melibatkan seluruh komponen masyarakat, dengan melihat situasi dan kondisi di luar sistem terkait dengan (extra systemic system) atau pemahaman secara makro dan di dalam sistem (intra sytemic system) atau pemahaman secara mikro sebagai suatu kesatuan. Hal ini terkait dengan Teori Fungsional dari Parsons (Johnson, 1986; Ritzer, et al, 2004) yang memuat empat fungsi yang diperlukan bagi kehidupan semua sistem dikenal sebagai skema A G I L, yaitu: (A) adaptation $(G)$ goal attainment, (I) integration (L) latency.

Diharapkan dengan hal tersebut, model pendekatan yang ditawarkan guna terjadinya perubahan perilaku ke arah yang dikehendaki pada diri anak jalanan, dapat berjalan secara efektif dan efisien. Hal ini senada dengan yang dikemukakan oleh Hurlock (1979) bahwa "sikap seseorang tidak hanya ditentukan oleh pribadi orang yang bersangkutan, tetapi juga ditentukan oleh faktor-faktor lingkungan, artinya sikap orang-orang di sekelilingnya terhadap diri orang yang bersangkutan”.

Terkait dengan hal di atas diperlukan pemahaman lebih mendasar tentang faktor-faktor apa yang berpengaruh terhadap perilaku anak jalanan. Kejelasan, kecermatan dan kebenaran penyajian data merupakan informasi dasar untuk merencanakan suatu pendekatan, termasuk pendekatan penyu-luhan sebagai salah satu strategi upaya pengentasan. Hal ini guna menunjang keefektifan pelaksanaan penanggulangan oleh pemerintah dan masyarakat yang terpanggil dan memiliki kepedulian terhadap permasalahan anak jalanan.

Berdasarkan hal di atas masalah penelitian ini yaitu seberapa besar latar bela-kang keluarga; latar belakang lingkungan; ciri fisik; ciri psikologik: ciri sosiologik berpengaruh terhadap perilaku anak jalanan di Bandung, Bogor dan Jakarta serta bagaimana strategi pengentasan anak jalanan di tiga wilayah penelitian tersebut.

\section{METODE PENELITIAN}


Penelitian ini merupakan penelitian deskriptif. Adapun bentuk metode deskritif yang digunakan (Nawawi, 1998) adalah Deskriptive Interrelationship CausalComparative Studies. Alasan menggunakan metode ini karena sifat dari penelitian yang bermaksud mengetahui dan menggambarkan faktor-faktor yang berpengaruh terhadap perilaku anak jalanan keterkaitannya dengan beberapa peubah, sekaligus menemukan strategi pengentasan yang efektif dan efisisien berdasarkan hasil penelitian.

Populasi dalam penelitian adalah anak jalanan yang ada di Bandung, Bogor dan Jakarta. Sampel ditentukan dengan menggunakan cluster random sampling. Cluster dipilih secara acak berdasarkan jenis kelamin. Sampel tiap kota 75 orang, terdiri dari 50 pria dan 25 wanita, dengan asumsi secara empirik memiliki rasio 2:1.

Penelitian dilakukan dengan menggunakan data primer dan sekunder. Data primer diperoleh dengan menggunakan kuesioner terstruktur, Focus Group Discus-sion dan pengamatan terlibat (participant ob-servation) sebagai pelengkap dan alat untuk mengecek data yang dihasilkan. Data sekunder diperoleh dengan cara studi dokumentasi dan studi literatur.

Validitas alat ukur dilakukan dengan menggunakan validitas konstruk, sedangkan reliabilitas dengan menggunakan teknik belah dua dengan cara membelah pertanyaan ganjil dari yang genap kemudian menggabungkan seluruh item tanpa dibelah untuk peubah-peubah yang diukur. Hasil analisis menunjukkan angka korelasi sebesar 0.7993 untuk peubah $\mathrm{X}$ dan 0.9177 untuk peubah $\mathrm{Y}$ yang berarti instrumen memiliki keterandalan yang cukup tinggi.

Data yang diperoleh dianalisis menggunakan statistik non parametrik dan parametrik dengan analisis jalur (path analysis) untuk mengkaji pengaruh langsung dan tak langsung dari peubah bebas terhadap sesama peubah bebas dan terhadap peubah terikat yang telah diduga atau diandaikan (Kerlinger, 1971).

\section{HASIL DAN PEMBAHASAN}

Gambar 1 memperlihatkan peubah latar belakang keluarga baik langsung maupun tidak langsung memiliki pengaruh yang nyata lebih besar terhadap perilaku anak jalanan, dibandingkan peubah lainnya. Hal ini memperlihatkan buruknya perilaku anak jalanan disebabkan terutama oleh buruknya latar belakang keluarga. Disamping disebabkan oleh buruknya latar belakang lingkungan, yang berpengaruh terutama terhadap ciri psikologik dan ciri sosiologik anak jalanan.

Pengaruh latar belakang keluarga terhadap perilaku anak jalanan secara nyata banyak disumbang oleh sub peubah pelaksanaan fungsi keluarga, terutama melalui ciri sosiologik. Sebaliknya nilai pengaruh latar belakang lingkungan terhadap perilaku anak jalanan secara nyata banyak disumbang oleh sub peubah penerapan sanksi terutama melalui ciri psikologik. Hal ini memiliki makna semakin buruk pelaksanaan fungsi keluarga baik pelaksanaan fungsi pengawasan, fungsi sosialisasi maupun fungsi ekonomi semakin nampak jelas perilaku menyimpang dari anak jalanan. Demikian pula faktor lingkungan, semakin buruk penerapan sanksi lingkungan terhadap pelanggaran yang dilakukan terutama oleh anak jalana : Jalur efektif semakin nampak penyimpangan perilak : Jalur paling efektif anak jalan

Gambar 2. Koefisien Path Pengaruh Sub P Terhadap Perilaku Anak Jalanan 


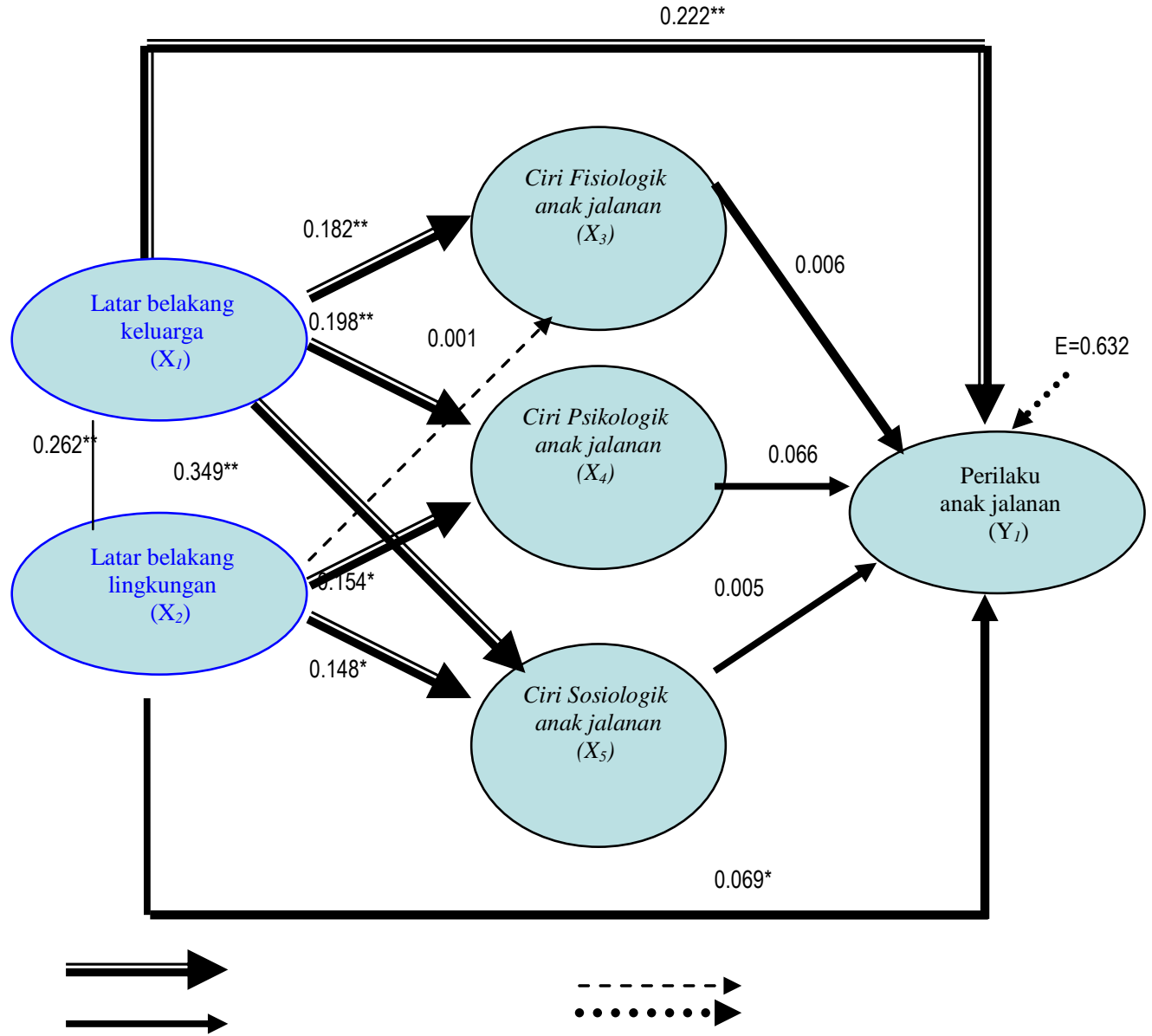

Gambar 1. Model Efektif Faktor yang Berpengaruh Terhadap Perilaku Anak Jalanan

Makna dari hal di atas upaya mengentaskan anak dari jalanan dengan cara mengubah perilakunya, perlu dilakukan melalui pendekatan keluarga terutama terkait dengan upaya menyeimbangkan pelaksanaan fungsi keluarga guna mengubah ciri-ciri sosiologik dari anak jalanan. Cara lainnya melalui pendekatan lingkungan terutama dengan penerapan sanksi lingkungan terhadap pelanggaran yang dilakukan melalui upaya merubah ciri psikologik anak jalanan.

Sub peubah ciri anak jalanan yang menyumbang relatif lebih besar meski tidak nyata terhadap perilaku anak jalanan adalah pendidikan formal. Hal ini memiliki makna rendahnya pendidikan formal menjadi penyebab utama anak turun ke jalan, sehingga menjadi penting melibatkan anak pada program pendidikan formal. Diharapkan dengan meningkatnya pendidikan formal yang dimiliki, dapat menggiring anak jalanan pada terjadinya perubahan perilaku yang melembaga karena didasari oleh terbukanya kesadaran dan pengetahuan anak. Dalam hal ini peubah dan sub peubah ciri anak jalanan tidak berpengaruh nyata terhadap perilaku anak jalanan, namun demikian tetap dapat digunakan sebagai bahan pertimbangan untuk dapat mengubah perilaku dan mengentaskan anak dari jalanan.

\section{Strategi Pengentasan Anak Jalanan}


Berdasarkan hasil penelitian, Pendidikan Nasional, Departemen Dalam peneliti menggembangkan "Strategi Negeri dan Kementrian Perbedayaan TRIBINA: Bina Manusia, Bina Lingkungan Perempuan), LSM, Swasta dan Masyarakat dan Bina Usaha", dalam upaya dengan menggunakan penyuluhan atau mengentaskan anak dari jalanan dan kegiatan belajar ataau pendidikan non fasilitas umum lainnya. Tersaji pada formal serta pendidikan formal yang Gambar 3, disusun berdasar pada skala dilakukan secara berkesinambungan. prioritas yang terdapat pada Gambar 2 .

Gambar 3 memperlihatkan strategi pengentasan anak jalanan, dapat dilakukan terutama dengan: memperbaiki pelaksanaan fungsi keluarga (bina manusia keluarga anak jalanan), meningkatkan pendidikan formal (bina manusia anak jalanan), melaksanakan penerapan sanksi yang nyata, jelas, tegas dan konsisten (bina lingkungan) yang dilakukan melalui bina usaha melibatkan pemerintah (dalam hal ini di antaranya Departemen Sosial, Departemen

Diharapkan dengan menggunakan prioritas utama dari Strategi TRIBINA, upaya dapat lebih efektif dan efisien untuk dapat mengubah perilaku anak jalanan, dari perilaku abnormal menjadi normal dan perilaku normal tetap bertahan bahkan meningkat. Dampak lebih lanjut dari terjadinya perubahan perilaku yang melembaga dalam diri anak jalanan ini, anak dapat terentaskan dari jalanan atau fasilitas umum lainnya.

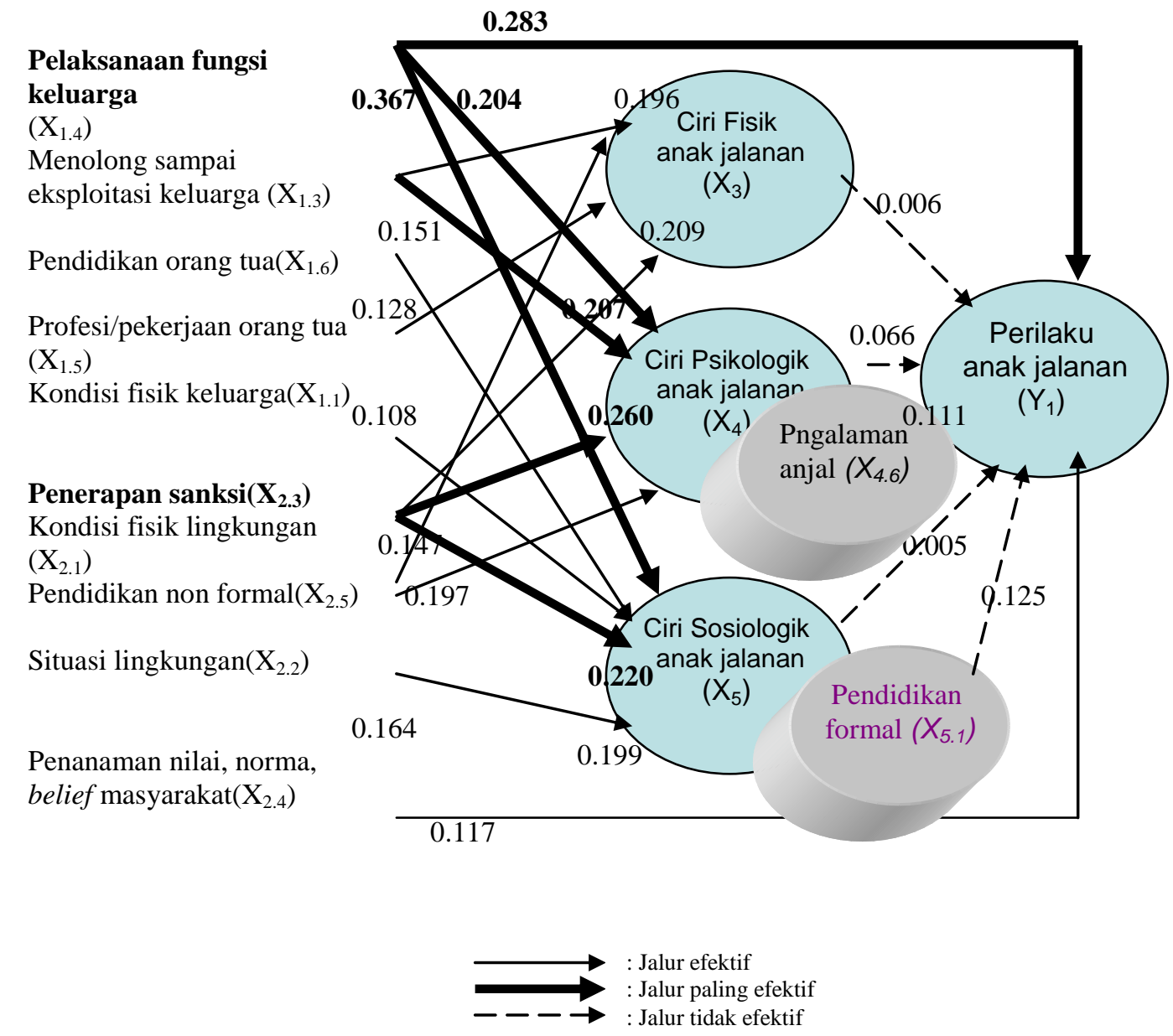

Gambar 2. Koefisien Path Pengaruh Sub Peubah Terhadap Perilaku Anak Jalanan 


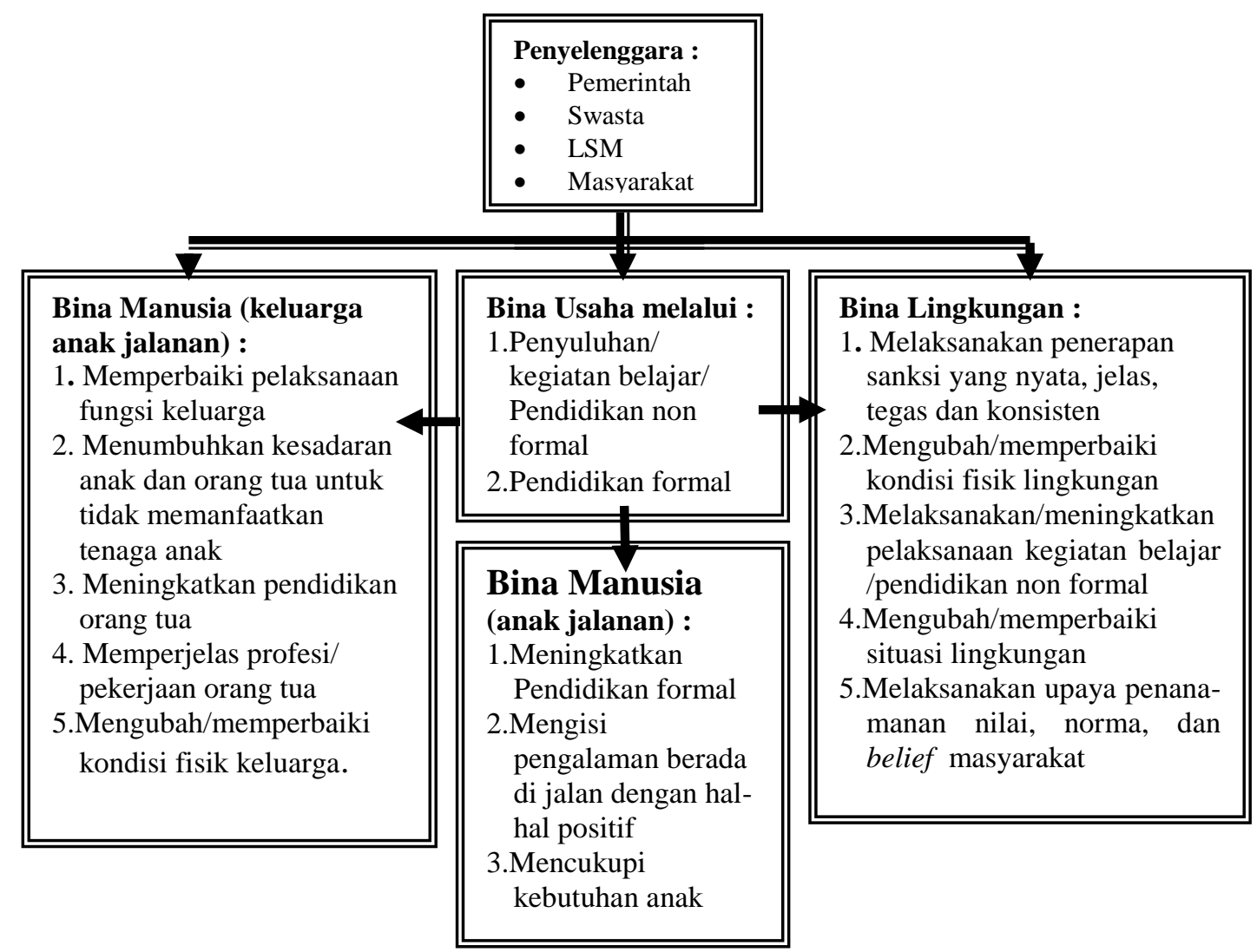

Gambar 3. Startegi Pengentasan Anak Jalanan

\section{KESIMPULAN}

Faktor-faktor yang berpengaruh nyata baik langsung maupun tidak langsung terhadap perilaku anak jalanan adalah latar belakang keluarga. Nilai pengaruh tersebut banyak disumbang oleh sub peubah pelaksanaan fungsi keluarga. Latar belakang lingkungan berpengaruh nyata melalui peubah ciri psikologik dan ciri sosiologik terhadap perilaku anak jalanan, namun hal ini tidak berpengaruh nyata melalui ciri fisik terhadap perilaku anak jalanan. Nilai pengaruh latar belakang lingkungan secara nyata lebih besar disumbang oleh sub peubah penerapan sanksi dan sub peubah kondisi fisik lingkungan terhadap perilaku anak jalanan.
Ciri fisik, ciri psikologik dan ciri sosiologik menunjukkan pengaruh nyata yang relatif kecil dibanding latar belakang keluarga dan latar belakang lingkungan terhadap perilaku anak jalanan. Namun berperan penting terhadap perubahan perilaku anak jalanan.

Strategi untuk mengentaskan anak dari jalanan dilakukan dengan menggunakan Stategi TRIBINA, yaitu Bina Manusia dan Bina Lingkungan yang dilakukan secara berkesinambungan dengan cara Bina Usaha yang melibatkan berbagai pihak baik Pemerintah, LSM, Swasta dan Masyarakat untuk bersama-sama melakukan kegiatan: Penyuluhan atau kegiatan belajar atau pendidikan non formal dan pendidikan formal. 


\section{DAFTAR PUSTAKA}

Hurlock, E. B. 1979. Personality Development. New Delhi: Tata Mc. Graw Hill Publishing Company Ltd.

Irwanto. 1996. Pekerja Anak di Tiga Kota Metropolitan: Jakarta, Surabaya dan Medan. Jakarta: Pusat Penelitian Atmajaya.

Johnson, P. D. 1986. Teori Sosiologi Klasik dan Modern. Diterjemahkan oleh Robert M. Z. Lawang. Jakarta: Gramedia.

Kerlinger, F. N. 1971. Foundation of Behavioral Research, 2th Ed,. New York: MacMillan.

Nawawi, H. 1998. Metode Penelitiaan Bidang Sosial. Yoyakarta: Gadjah Mada niversity Press.

Popenoe, D. 1989. Sociology. $7^{\text {th }}$ ed. Prentice hall, Englewood Cliffs. New Jersey 07632.

Ritzer, G. dan Godman, J. D. 2004. Teori Sociology Modern. Terjemahan. Tribuwono BS. Jakarta: Kencana.

Sudrajat, T. 1996. Peranan LSM (YKAI) Dalam Menangani Masalah Anak Jalanan. Seminar Sehari. Sekolah Tinggi Kesejahteraan Sosial. Bandung.

Sulistiati. 2001. Model Pendekatan Terpadu Untuk Memecahkan Masalah Anak Rawan. Universitas Pendidikan Indonesia. Bandung (Disertasi).

Tjahjorini, S. 2001. Persepsi Anak Jalanan Terhadap Bimbingan Sosial di Rumah Singgah di Kotamadya Bandung. Bandung. 2001 (Tesis). 